\title{
Bronchomotor tone and its modification by certain drugs
}

\author{
P. L. KAMBUROFF \\ Ph.D., M.Sc., D.I.C. \\ Respiratory Physiology Laboratories, Cardiothoracic Institute, London SW3 6HP
}

\begin{abstract}
Summary
The bronchial smooth muscle is described and its autonomic innervation discussed. The effect of certain physiological substances on the smooth muscle is discussed and also the consequence of blockade of the alpha receptors of the sympathetic nervous system. Indoramin, a powerful alpha blocker is also antihistaminic and this drug has been used therapeutically in the treatment of some asthmatics. Prostaglandin $F_{2}$ beta has not yet been applied in human subjects.
\end{abstract}

THE main function of the smooth muscle of the lung is to control the distribution of inspired gas entering the lung, but it is well to remember that smooth muscle is also a component of the pulmonary vasculature and that factors which affect the calibre of the bronchi may also affect the pulmonary arteries. Changes in bronchomotor tone also produce secondary effects on the state of distension of the pulmonary alveoli and these in turn may produce a mechanical effect on the thin-walled alveolar capillaries and venules. Thus, changes in bronchomotor tone may also effect changes in the flow and distribution of blood in the lung quite apart from any effects on vascular smooth muscle.

Bronchial smooth muscle is distributed from the trachea downwards as far as respiratory bronchioles, but its attachments vary, so that the effects of muscle contraction are different in the largest air channels from the effects in the smaller ones. In the trachea and main bronchi which have incomplete cartilagenous supporting rings the muscle is arranged horizontally being attached to the inner aspects of the tips of the cartilage. Contraction of this part of the bronchial muscle can therefore reduce the diameter of the trachea and main bronchi quite dramatically. Changes in bronchial diameter occur during the respiratory cycle, dilatation during inspiration and constriction during expiration; the reason for this is not only mechanical stress on the bronchi from the adjacent elastic structures of the lung, but it may also correspond to changes in muscular tone.

The muscular attachment to cartilage disappears at the level of the hilum of the lung and from there onwards the direction of the fibres becomes more oblique. Contraction of the muscle here produces

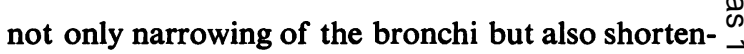
ing. Muscle fibres in this part of the bronchial tree? move in the submucosal layers having no direct $\overrightarrow{\vec{\omega}}$ attachment to cartilage. One important aspect of the $\stackrel{\sigma}{\omega}$ distribution of muscle fibres is that they influence the 8 stability of the airways and can probably prevent 3 . closure of these airways (Kemm and Kamburoff, in 1970): it is doubtful whether here cartilage has any o stabilizing function at all.

An important point to bear in mind is that the mass of muscle in proportion to the diameter of the $\mathscr{\varnothing}$ airways increases as these are traced distally from 을 the hilum and as a result contraction of the muscle in the distal parts produces a far greater proportional $\rightarrow$ decrease in cross-section of the whole bronchial tree than it does in the more proximal parts where $\overrightarrow{0}$ the initial diameter of the airways is greater.

\section{Nervous control of bronchial muscle}

The sympathetic innervation is in general inhibitor in its actions but many years ago Dixon and Ransom $\frac{0}{\mathrm{D}}$ (1912) noted that sympathetic stimulation of certain $\cong$ fibres of the cervical sympathetic nerves causes $\overrightarrow{\overline{0}}$ bronchoconstriction in cats. This dual activity of the sympathetic system on the bronchi is now attributed to differences in the response to stimulation of the post-ganglionic nerve endings. Later the concept of $\frac{}{2}$ chemical mediators was elaborated by Dale (1935) and many others since and, finally, by the work of $\frac{}{3}$ Alhquist (1966) and Lands et al. (1967), who introduced the idea of specific receptors which were the $\frac{3}{3}$ site of activity of agents which stimulate or inhibit the contraction of muscle. Explanations of the modes $?$ of action of sympathomimetic drugs has led to the $\frac{D}{0}$ hypothesis that specific receptors exist on the surfaces of the muscle cells which have been grouped o into two main categories: those which produce $N$ bronchoconstriction when stimulated by noradrena- N line which are called ' $\alpha$-receptors' and those which $\omega$ respond to isopropylnoradrenaline (isoprenaline), the $\beta$-receptors. In addition to their bronchial effects, $\stackrel{\varrho}{\subseteq}$ $\alpha$-stimulants also relax the smooth muscle of the gut $\stackrel{\Phi}{\Phi}$ and cause contraction of the sphincters; they increase? heart rate and produce vasoconstriction and mobilize fat. The $\beta$-receptors increase heart rate and the force 
of contraction of the heart muscle, produce vasodilatation and often eosinophilia and mobilize glucose from liver glycogen. Beta-receptors have been further subdivided on pharmacological grounds into two subgroups, $\beta_{1}$ and $\beta_{2}$, the main distinction between these being that the latter are mainly concerned with regulation of bronchomotor tone and have relatively little effect on the cardiovascular system.

The main motor innervation of the bronchi comes from the pulmonary branches of the vagus nerve. The nerve cells on the final path of motor impulses are situated actually in the muscle mass which is unlike the distribution of the sympathetic fibres which arise in cells aggregated in the sympathetic ganglia. The main way in which parasympathetic innervation can be controlled by external means is, of course, by stimulating or paralysing the parasympathetic nerve endings with acetylcholine or atropine. It is worth-while noting that bronchoconstriction is the only true stimulant effect on the bronchial smooth muscle; bronchodilatation is essentially a passive phenomenon resulting from a reduction in bronchomotor tone. In the intact animal the state of dilatation of the bronchi may be looked upon as an equilibrium between inhibitor and excitor impulses. It seems likely that in the normal subject there is very little bronchomotor tone since it requires high doses of either bronchodilator or bronchoconstrictor drugs to produce measurable effects on airway calibre. In states of heightened bronchomotor tone the situation is quite otherwise. In asthmatic subjects in remission, for example, it has many times been observed that even though ventilatory capacity and airways resistance may be within normal limits, the effects of these drugs are much more easily seen.

In addition to these directly nervous influences, there are many tissue mediators such as histamine, 5-hydroxytryptamine, serotonin, bradykinin, prostaglandin or dopamine which are known to have important effects on airway calibre. This makes the interpretation of changes in airway calibre as a result of administration of drugs difficult to interpret since there are so many degrees of freedom amongst the factors which, in the end, are responsible for maintaining bronchomotor tone. Disturbance of one of these may produce a balancing effect from the others and may result in unexpected consequences.

Recently, interest has been displayed in the effects of blockade of the $\alpha$-receptors of the sympathetic nervous system. Whilst in the normal subject this has little effect, in asthmatics and some bronchitic patients clinically useful bronchodilatation may be produced by the use of $\alpha$-blocking drugs.

The main factors which influence bronchomotor tone are summarized in Table 1.

TABLE 1. Showing the main factors which influence bronchomotor tone

Dilatation Constriction

(1) Sympathetic efferent stimulation

(2) Adrenaline

(3) Sympathomimetic drugs: $\beta$-receptor stimulants $\alpha$-receptor blockers Theophylline and other xanthine derivatives Ephedrine

(4) Atropine and analogues

(5) Local anaesthetics

(6) Prostaglandins (e.g. $\mathrm{E}_{2}$ and $F_{2} \beta$ )
(1) Vagal efferent stimulation

(2) (a) Acetylcholine (b) Methacholine

(3) $\alpha$-adrenoceptor stimulants

(4) $\beta$-adrenoceptor blocking drugs

(5) Local mechanical and chemical irritation *

(6) Hypoxia *

(7) $\mathrm{CO}_{2}$ excess *

(8) Prostaglandins (e.g. $F_{2} \alpha$ )

(9) (a) Histamine

(b) 5-hydroxytryptamine

(c) Bradykinin

(d) SRS-A

* Local axon, chemoreceptor and central reflexes are involved in these responses.

\section{Clinical applications}

The clinical applications of the facts outlined above are mainly directed towards reducing bronchomotor tone. There is, as everyone knows, a large variety of pharmacological agents which are capable of doing this, all of which act through the $\beta$-receptors of the sympathetic nervous system. The first drug to be used in this connection was adrenaline and this remained the standard means of treating asthmatic attacks until the work of Lands and his colleagues (1947) established the use of isoprenaline. The advantage which this drug has over adrenaline is that it has no effect on the $\alpha$-receptors of the sympathetic nervous system. This fact is important because it has been stated that adrenaline which has mixed $\alpha$ - and $\beta$-stimulant functions, may sometimes fail to produce bronchodilatation in asthmatics, possibly because of a large proportion of $\alpha$-receptors in these patients. In recent years there has been a concentrated effort to search for more specific $\beta_{2}$-stimulant drugs and a typical example of this was the discovery of salbutamol; many similar specific $\beta_{2}$ drugs have been synthesized since this drug was introduced. Work which was carried out in our laboratories established the specificity of salbutamol in comparison with isoprenaline by showing that the effect of the latter on heart rate was in fact some seven to ten times greater than that of salbutamol whilst the ventilatory effects were similar (Paterson, Courtenay Evans and Prime, 1971). Much research work has been carried out to assess effectiveness of the large range of $\beta_{2}$-adrenergic drugs. These have shown that in general their potency is about the same. This means that corresponding proportional increments in dose of drug produce the same increments in, for

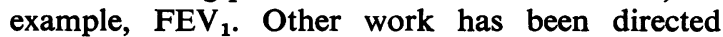
towards finding the best way of administering these 


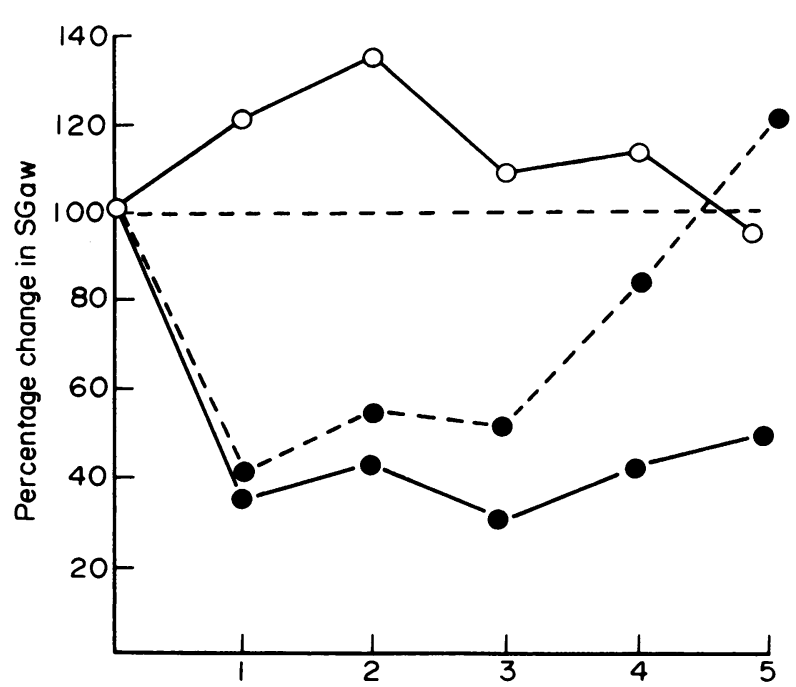

Fig. 1. Shows the effect of inhaling histamine $(400 \mu \mathrm{g})$ on Specific Airways Conductance $\left(\mathrm{SG}_{\mathrm{aw}}\right)(\mathrm{O}-\mathrm{O})$ and the reduction in the response $10 \mathrm{~min}(0 \ldots)$ and $90 \mathrm{~min}(\mathrm{O}-\mathrm{O})$ after the i.v. injection of $8 \mathrm{mg}$ indoramin.

drugs and has shown that multiple small doses by inhalation are much more effective than single large doses (Prime and Kamburoff, 1972).

All this group of bronchodilator drugs antagonize the bronchconstrictor activity of histamine. Histamine inhaled by normal subjects in sufficient doses produces an evanescent bronchoconstriction (see Fig. 1, lowest line) (Kamburoff, Griffin and Bianco, 1972). This comes on a few seconds after inhalation and lasts a maximum of $10 \mathrm{~min}$; we find that in individual cases the reaction to histamine is remarkably reproducible. This finding has been used to assess the duration of activity of various $\beta$ stimulant drugs and also to assess their efficacy in normal subjects before giving them to patients.

While working with histamine we felt that it would be instructive to measure the effect of $\beta$-receptor blocking drugs on bronchomotor tone. For this purpose we used propranolol. We found that $80 \mathrm{mg}$ taken by mouth was sufficient to produce some reduction in specific airways conductance, i.e. induce some degree of reduction in the diameter of the airways. This effect was dose-related in healthy individuals. We found that $160 \mathrm{mg}$ by mouth produced a degree of bronchoconstriction which, although not noticeable by normal subjects, can easily be detected with the whole body plethysmograph. This effect lasts for some hours (Fig. 2). The relationship between bronchoconstriction produced by propranolol and that produced by stimulation of the vagus nerve endings by, for example, acetyl-

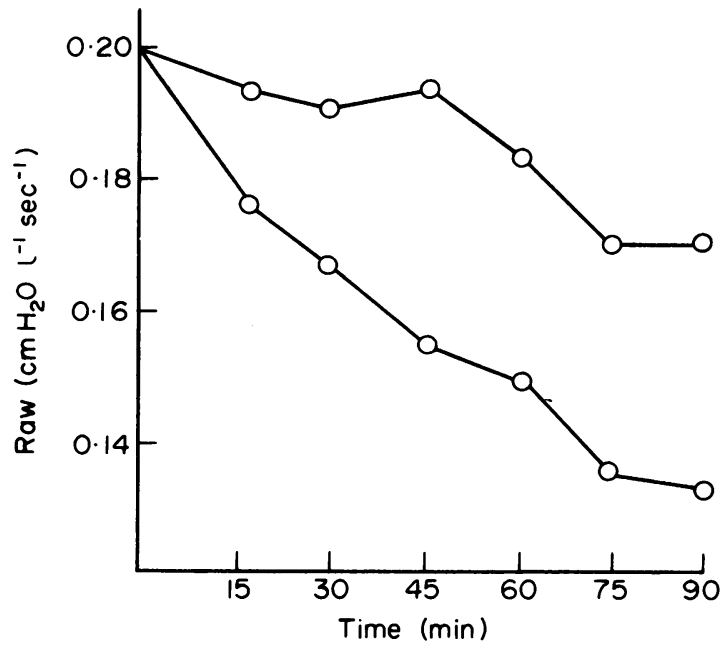

FIG. 2. Shows the effect on airways resistance $\left(R_{a w}\right)$ of administering $80 \mathrm{mg}$ (upper curve) and $160 \mathrm{mg}$ (lower curve of propranolol to a normal adult male subject.

choline, has not been fully elucidated. It is true, however, that the blocking effect of propranolol can be antagonized by atropine and can be swamped by sufficiently large doses of $\beta$-stimulant drugs since propranolol is a competitive antagonist of $\beta$ 을 activity. The bronchoconstrictor activity of proprano lol is of some importance therapeutically because it asthmatic patients and in some bronchitics there seems to be a heightened sensitivity to its effects. This has led to deaths in bronchitic patients who have been given $\beta$-blocking drugs for the treatment of angina pectoris or cardiac arrhythmias. The heightened sensitivity to these drugs in asthmatic patients may be exaggerated by the known $\beta$-blocking activity of certain bacterial toxins.

Our work in this field led us to consider the place of $\alpha$-receptor blockade in the maintenance of bronchomotor tone. The first drug which we used in this work was thymoxamine because this was stated to be a highly specific $\alpha$-blocker. Most $\alpha$-blockers are also antihistaminic in their action. We found that the bronchoconstriction produced by histamine could be almost completely reversed by the administration of thymoxamine and that this effect was dose-related (Bianco et al., 1972). At that time it seemed likely that this was solely due to $\alpha$-receptor inhibition. Subsequent work has made it apparent that thymoxamine also has quite powerful antihistaminic properties and that these may have played an important part in the inhibition of histamine-induced bronchoconstriction. We extended this work with thymoxamine by using it to demonstrate the existence of $\alpha$-receptors in the human bronchial muscle (Prime et al., 1972). 


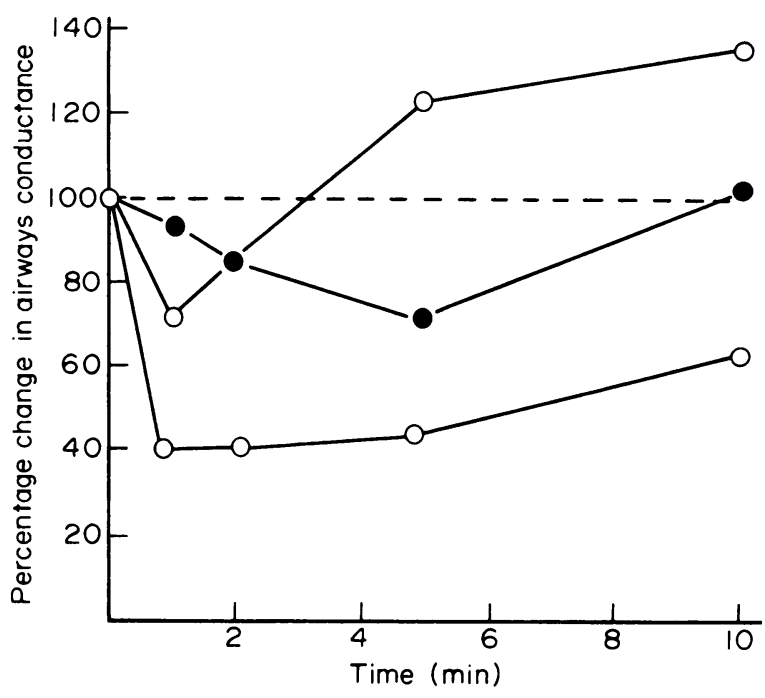

FIG. 3. Alpha adrenoceptor blockade by indoramine ( $8 \mathrm{mg}$ i.v.) after propranolol. The line joining the solid circles shows the effect of inhaling $0.96 \mathrm{mg}$ of phenylephrine in an adult male subject who was atopic but not asthmatic; a small fall in specific airways conductance is seen about $5 \mathrm{~min}$ later. The lower line (open circles) shows the effect of the same procedure $45 \mathrm{~min}$ after ingestion of $160 \mathrm{mg}$ of propranolol: a much larger fall in $\mathrm{SGaw}$ is seen. The uppermost line (open circles) shows the effect after taking both propranolol by mouth and injecting $8 \mathrm{mg}$ of indoramin intravenously. It shows a small initial fall in conductance followed by an increase.

The method which we used was to paralyse the $\beta$-receptors in normal volunteer subjects with a sufficient dose $(160 \mathrm{mg})$ of propranolol taken by mouth. We then administered $0.96 \mathrm{mg}$ phenylephrine by inhalation; this drug is mainly $\alpha$-adrenergic stimulant in its action but has also some $\beta$-stimulant effects which were blocked by the propranolol. We found that the bronchoconstriction produced by propranolol was exaggerated by taking the phenylephrine and that this latter effect could be abolished by pretreatment with thymoxamine. Another drug which is available, having somewhat similar actions to thymoxamine, is indoramin. In addition to being a powerful $\alpha$-blocker this has almost equally powerful antihistaminic actions. It also can abolish the effect of phenylephrine in the $\beta$-blocked subject (Fig. 3) in the same way as thymoxamine but it has the great advantage of more prolonged action. We have used this drug therapeutically and find that it has an added effect when used with $\beta$-stimulant drugs and that its sedative actions may also be beneficial to some asthmatics (Kamburoff, Prime and Schmidt, 1976).

\section{Anticholinergic drugs}

The knowledge that the motor nerve supply to the bronchi was through the vagus explained the beneficial effects of this group of drugs on asthmatics. The use of galenical preparations containing substances such as atropine and strophanthin has been standard medical practice for centuries. The discovery of adrenaline coupled with its great potency and the subsequent discovery of specific $\beta$-stimulant drugs has rather overshadowed the value of anticholinergic drugs in more recent years. Lately, there has been renewed interest in these because new drugs having somewhat more specific effects than atropine itself have been discovered, one of which is a drug known as SCH 1000 which we find to be an effective bronchodilator which has fewer side effects than atropine itself (Günther and Kamburoff, 1974). Deptropine is another such drug but this unfortunately tends to produce as much in the way of side effects as atropine (Prime, 1968). Atropine or deptropine are sometimes combined with isoprenaline with the idea that their effects are additive and also in order to prolong the rapid onset of bronchodilatation induced by isoprenaline alone.

\section{Prostaglandins}

Great interest was aroused by the discovery of a large series of prostaglandins which are synthesized in the lung. These are both bronchoconstrictor and bronchodilator in action and it is possible to obtain these fractions in isolation. We find that bronchoconstriction induced by prostaglandin $F_{2} \alpha$ in minute doses in normal subjects can be inhibited by $\beta$-stimulant drugs and by indoramin. The bronchodilator fraction known as $F_{2} \beta$, although well documented in animals, has not yet been successfully applied in human subjects. So far, work on these drugs has not opened up any definite possibility of using them therapeutically.

\section{References}

AhlQuist, R.P. (1948) Study of adrenotropic receptors. American Journal of Physiology, 153, 586.

AHLQuist, R.P. (1966) The adrenergic receptor. Journal of Pharmaceutical Sciences, 55, 359.

Bianco, S., Griffin, J.P., Kamburoff, P.L. \& Prime, F.J. (1972) The effect of thymoxamine on histamine induced bronchospasm in man. British Journal of Diseases of the Chest, 66, 27.

Dale, SIR Henry (1935) Pharmacology and nerve-endings. Proceedings of the Royal Society of Medicine, 28, 319.

Dixon, W.E. \& RANSOM, F. (1912) Bronchodilator nerves. Journal of Physiology, 45, 413.

GÜNTHER, W. \& KAMBUROFF, P.L. (1974) The bronchodilator effect of a new anticholinergic drug, Sch 1000. Current Medical Research and Opinion, 2, 281.

Kamburoff, P.L., Griffin, J.P. \& Bianco, S. (1972) The use of histamine-induced bronchoconstriction as a method for investigating bronchodilator drugs. British Journal of Diseases of the Chest, 66, 21.

Kamburoff, P.L., Prime, F.J. \& Schmidt, O-P. (1976) The bronchodilator effects of rimiterol and indoramin. (In press.) 
Kemm, J.R. \& KamburofF, P.L. (1970) Effort and the forced expiratory volume in one second $\left(\mathrm{FEV}_{1}\right)$. Clinical Science, 39, 747.

Lands, A.M., Arnold, A., McAuliff, J.P., Luduena, F.P. \& BRowN, T.G. (1967) Differentiation of receptor systems activated by sympathomimetic amines. Nature. London, 214, 596.

Lands, A.M., Nash, V.L., McCarthy, H.M., Granger, H.R. \& Dertinger, B.L. (1947) Pharmacology of N-alkyl homologues of epinephrine. Journal of Pharmacology and Experimental Therapeutics, 90, 110.

Paterson, J.W., Courtenay Evans, R.J. \& Prime, F.J. (1971) Selectivity of bronchodilator action of salbutamol in asthmatic patients. British Journal of Diseases of the Chest, 65, 21.

Prime, F.J. (1968) The relief of airways obstruction by deptropine citrate and isoprenaline. British Journal of $c$ Diseases of the Chest, 62, 81.

Prime, F.J. \& KamburofF, P.L. (1972) Single shots versus divided doses of a bronchodilator in the relief of reversible airways obstruction. Lancet, i, 753.

Prime, F.J., Bianco, S., Griffin, J.P. \& Kamburoff, P.L. (1972) The effects on airways conductance of alphaadrenergic stimulation and blocking. Bulletin de Physiopathologie Respiratoire, 8, 99. 